\title{
Article
}

\section{Cost Allocation in Integrated Community Energy Systems-Social Acceptance}

\author{
Na Li *(D, Rudi Hakvoort and Zofia Lukszo (D) \\ Faculty of Technology, Policy and Management, Delft University of Technology, Jaffalaan 5, \\ 2628 BX Delft, The Netherlands; R.A.Hakvoort@tudelft.nl (R.H.); Z.Lukszo@tudelft.nl (Z.L.) \\ * Correspondence: n.l.li@tudelft.nl
}

Citation: Li, N.; Hakvoort, R.; Lukszo, Z. Cost Allocation in Integrated Community Energy Systems-Social Acceptance. Sustainability 2021, 13, 9951. https:// doi.org/10.3390/su13179951

Academic Editors: Johannes Reichl, Simona D'Oca and Yuvaraja Teekaraman

Received: 30 July 2021

Accepted: 31 August 2021

Published: 4 September 2021

Publisher's Note: MDPI stays neutral with regard to jurisdictional claims in published maps and institutional affiliations.

Copyright: (c) 2021 by the authors. Licensee MDPI, Basel, Switzerland. This article is an open access article distributed under the terms and conditions of the Creative Commons Attribution (CC BY) license (https:/ / creativecommons.org/licenses/by/ $4.0 /)$.

\begin{abstract}
Integrated community energy systems (ICESs) are a good representative of local energy systems by integrating local distributed energy resources and local communities. It is proposed that costs should be allocated in a socially acceptable manner since there is no regulation in ICESs. In this paper, social acceptance is conceptualized from the dimension of community acceptance considering procedural and distributive justice. A fair process increases the understanding and the acceptance of the cost allocation outcomes, and a fair outcome leads to the acceptance of the cost allocation procedure. This approach adopted the multi-criteria decision-making technique to evaluate social acceptance to select a cost allocation method that was socially acceptable to local community members. The results show that our approach is unique and useful when multiple decision-making groups have to decide together upon the cost allocation method. It is able to provide quantitative results and optimal decisions from a multi-group decision-making perspective. The methodology developed in this research can be applied to any local community energy system to select a cost allocation method. Furthermore, the obtained results can be used by decision-makers to support them in the decision-making process. Based on our approach, policy implications are also analyzed to support the success of cost allocation in ICESs.
\end{abstract}

Keywords: integrated community energy systems; cost allocation; social acceptance; distributive justice; procedural justice; multi-criteria decision-making

\section{Introduction}

\subsection{Background and Motivation}

Energy becomes more flexible, decentralized, and localized with the integration of DERs at the local level. Local energy systems aim to meet local demand with local DERs in a given (local) geographical area [1,2]. Local DERs bring energy generation closer to consumers, therefore reducing complexity, cost, and inefficiencies compared to a centralized energy system. Local energy systems are also the key enablers in the transition to the net-zero carbon era and future energy systems. Integrated community energy systems (ICESs) are a good initiative to deal with the transition of the local energy landscape by integrating local DERs and local communities [3,4]. Local energy systems are important for self-sufficiency and sustainability, ICESs provide an approach for system integration and a platform where local communities can take full control of their energy system and capture all the benefits brought by this [5]. ICESs utilize the technical values of community microgrids and social and economic values of integrated energy systems to make them robust, reliable, and secure [4].

ICESs provide various options to promote the engagement of local community members, such as investment, ownership, local energy exchange, and economic incentives [6]. Individual households are the basic units of local communities, and they are interconnected with each other in ICESs. They must be motivated to adopt flexible consumption habits to match demand with the supply of volatile energy sources. Local communities are changing 
their roles from consumers to prosumers with local generation, demand response, and energy efficiency measures [7]. The two fundamental components of ICESs are local DERs and local communities. A basic structure of an ICES is shown in Figure 1. The ICES is equipped with community generations (solar panels and wind turbines), community storage, a community energy management system, and local community members (consumers and prosumers). The system can work both in grid-connected mode to get support from the grid since the local generations from solar panels and wind turbines are intermittent, and off-grid mode to be self-sufficient by utilizing the flexibility provided by local storage systems. Local DERs bring generation close to local members and they also have the opportunity to be the owner of the energy system by investing in both community and individual DERs. The penetration of local DERs in local community energy systems makes the local communities actively participate in the energy transition at the local level.

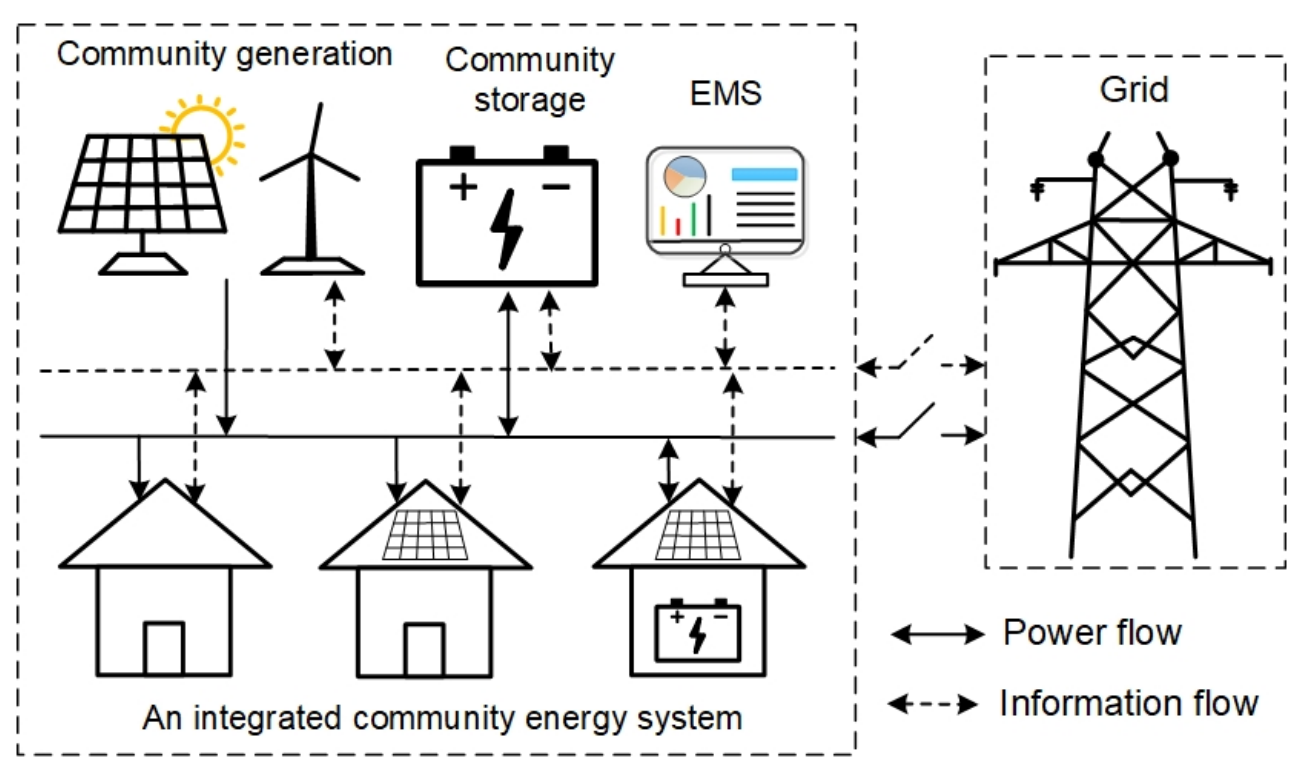

Figure 1. A basic structure of an integrated community energy system.

Many barriers exist in the implementation and adaptation of ICESs, where the issues vary from technical, socio-economic, environmental to institutional aspects, which are extensively illustrated in the study [6]. The implementation of ICESs is often treated as a technical task. However, the essential social-economic aspects are mostly neglected, such as social acceptance and cost allocation. The investment of ICESs has the characteristic of community-owned [4], each member should pay for the cost they cause, and the free-rider behavior is not appreciated in an ICES. Fair cost allocation also promotes the cooperation of the local community and contributes to the long-term development of ICESs [8]. Cost allocation should reflect all the costs involved in ICESs, such as capital cost, operation and maintenance cost, and customer service cost as well as local energy management system cost. These costs must be allocated among the local communities fairly to prevent free-rider behavior. Consumers should pay for the cost they incur, and prosumers should not only pay for the cost they incur, but also get the revenue for the energy they share in the community. A fair cost allocation is the key factor that affects the success of ICESs.

One of the novel aspects of ICESs lies in the integration of local community members [9]. They play an important role in the energy system by actively involving in the planning, development, and administration of the energy system as well as the allocation of its costs and benefit. Local community members are encouraged to participate in the decision-making process. In addition, they may have different situations in, such as educational background, employment, financial issues, skills, experience, personality, energy demand, etc. $[10,11]$. Therefore, they may have various preferences towards cost allocation. The selected cost allocation method should satisfy the requirements and preferences of local community members. Furthermore, no regulators are involved in ICESs, the community 
itself needs to agree on the cost allocation method themselves. It, therefore, requires that the selected cost allocation method be socially acceptable to local stakeholders. Studies in this area are often missing; therefore, it is necessary to review the topic of social acceptance in relevant areas to see what lessons can be learned and how they can be applied in the context of cost allocation in ICESs.

\subsection{Literature Review}

\subsubsection{Social Acceptance in Renewable Energy Projects}

A growing number of literature has addressed the issue of social acceptance of renewable energy technologies, especially wind energy [12-14]. These studies investigate the factors that affect social acceptance of wind energy projects by using empirical studies from various aspects: social perspective [15], economic and financial perspective [16], and ownership perspective [17]. The original conceptualization of social acceptance of renewable energy innovation is introduced by Wüstenhagen et al. [18] and three dimensions are addressed: social-political, market, and community acceptance. Social-political acceptance refers to the acceptance of technologies, policies, and institutional changes by key stakeholders and policy actors [19]. Market acceptance reflects the acceptance of various stakeholders (consumers, investors, and other relevant stakeholders) in the commercialization process of the project [18]. Community acceptance addresses the issue to what extent the decisions are acceptable to local stakeholders, residents, and local authorities of the local-based projects [20].

Community acceptance is mainly addressed in the study on social acceptance of renewable energy projects among the three dimensions [21,22]. The factors that are mainly influencing community acceptance are distributive justice and procedural justice [18,23]. Distributive and procedural justice are also widely used in the study of energy justice to guarantee fair and equitable access to resources and technologies in the process of the energy transition [24-26]. Distributive justice focuses on how the costs and benefits are distributed fairly, which is the critical factor to support the implementation of the projects [27]. It is generally used to evaluate the fairness of the outcomes [28,29]. The study in [30] analyzes the factors that affect the distributive justice on wind projects (fair distribution of the benefits and burdens of wind energy projects) by means of interviews among local citizens. Procedural justice focuses on the process of decision-making, it requires that all the stakeholders are treated in a non-discriminatory manner [31]. It states that all the stakeholders should be able to participate in the decision-making process equitably, and their points of view are thoroughly taken into consideration [20]. Furthermore, it demands that all the stakeholders are accessible to all the relevant information. Procedural justice is essential to increase community acceptance [12]. Both procedural and distributive justice are addressed in the analysis of community acceptance of wind energy projects by [23]. Three levels of engagement: information, consultation, and participation are analyzed for procedural justice, and financial participation of local citizens and other stakeholders are analyzed for distributive justice. In summary, the study of social acceptance of renewable energy projects is mostly focused on the community acceptance dimension in terms of the two key aspects: distributive and procedural justice. In the context of cost allocation in ICESs, the objective is to allocate costs in a socially acceptable manner by taking local community members' opinions into account. Both the process and the results of cost allocation should be fair and acceptable to local community members in ICESs. Therefore, the analysis of social acceptance should start from the dimension of community acceptance by taking the two aspects of procedural and distributive justice into account, which is most relevant to this research. It is essential to define proper criteria that affect procedural and distributive justice, which will be further discussed in the following part of this research.

Besides, many methods can be used to allocate costs in ICESs according to our previous study [32]. For instance, the costs can be allocated based on energy pricing per $\mathrm{kWh}$, or capacity pricing per $\mathrm{kW}$, or the number of customers, or any combination of these. Each cost allocation method has different performance over various criteria, such as cost causality 
and cost reflectiveness $[33,34]$. Local community members have various preferences over these criteria. Some may prefer that the costs are allocated to the drivers that made it, while others may prefer to pay the energy bills that reflect the cost they should pay. There is no consensus on which is the best cost allocation method. Local community members need to agree on the approach, which can satisfy their preferences the most, thus being socially acceptable to them. Furthermore, local community members with similar backgrounds and interests may have similar or the same preference over the criteria. Therefore, they can be classified into several groups according to their major preferences. It, therefore, stands for a multi-alternative, multi-group, multi-criteria, and decision-making problem. The method that can handle this problem is multi-criteria decision-making (MCDM), which can take the preferences of all the stakeholders into account and further assist their decision-making (select a cost allocation method). Therefore, MCDM methods for dealing with multi-group decision-making will be introduced in the next section.

\subsubsection{MCDM in Multi-Group Decision-Making}

MCDM techniques are considered an effective tool for supporting decision-makers to take decisions while considering all the criteria and objectives simultaneously with multiple alternatives [35,36]. In general, the criteria and objectives are conflicting; therefore, the solution of the decision-making problem highly depends on the interests and preferences of the decision-makers [37]. MCDM techniques have been applied substantially on the subjects of evaluating and comparing sustainable and renewable energy options [38,39], energy storage options [40,41], energy planning [11,42], and energy policies [43,44]. MCDM techniques are used to compare the performance of each option with certain criteria. The criteria considered cover many aspects from technical, economic, social, institutional to environmental perspectives [45]. The option that is ranked with the highest score is deemed to be the best choice for the considered MCDM problem [46].

The reviews of $[42,45]$ give good overviews of earlier studies on MCDM in the application of sustainable energy decision-making. The commonly used methods for multi-group decision-making are analytic hierarchy process (AHP), elimination et choice translating reality (ELECTRE), preference ranking organization method for enrichment evaluation (PROMETHEE), and technique for order preference by similarity to ideal solution (TOPSIS). The AHP method decomposes the decision-making problem into a hierarchy problem with the goal in the top layer, criteria in the middle level, and alternatives at the bottom layer [47]. It selects the alternative based on pair-wise comparison according to the expert judgments $[48,49]$. ELECTRE and PROMETHEE methods rank the alternatives by utilizing the outranking relation between alternatives based on pair-wise comparisons [50,51]. TOPSIS is a useful technique for the application of MCDM problems in a group decision-making environment to select a suitable alternative [52,53]. It considers both the positive and negative ideal solutions and alternatives are ranked according to their relative closeness. The ideal solution has the shortest distance from the positive ideal solution and the farthest distance from the negative ideal solution [54,55]. Among these methods, TOPSIS offers a simple way of combining the preferences of multiple groups for group decision-making, which is the most relevant to this research. It is the most commonly used method in the sustainable supplier selection problem [56-58]. A multi-criteria intuitionistic fuzzy TOPSIS method is applied for the evaluation of supplier problems with multi-decision-making groups [56,57]. The study in [58] proposes an extended TOPSIS method and applies it in the sustainable supplier selection problem to deal with the multiple decision-making groups with different concerns. Besides, the TOPSIS method is adopted to solve the decision-making of a multi-objective regional energy system planning problem by taking a multi-actor perspective by Wang et al. [59]. Overall, the TOPSIS technique is an effective technique to deal with MCDM problems with multiple decision-making groups. 


\subsection{MCDM for Social Acceptance Analysis}

Social acceptance is always difficult to achieve and analyze, no matter in whichever system. Furthermore, decision-making with multiple criteria, multiple alternatives, and multiple decision-making groups is always a complex task to implement. Our literature review shows that the problem of social acceptance and MCDM in renewable energy projects has been studied extensively. However, the study of using MCDM to analyze to what extent the alternative is socially acceptable and thus to select the best solution has not often been addressed. Considering the objective of the study, MCDM is considered an effective tool to select a socially acceptable cost allocation approach. It enables a critical evaluation and analysis of the multiple alternatives considering the criteria defined, and finally identifies a socially acceptable cost allocation approach considering the preferences and interests of multiple decision-making groups involved in the energy systems. This approach can be applied in any local energy system that is focusing on the social acceptance of local stakeholders.

\subsection{Knowledge Gap and Contributions of the Paper}

There are no regulators in ICESs, the community itself needs to select a method to allocate the costs. The stakeholders involved in the community may hold different points of view towards cost allocation in ICESs. Therefore, the costs should be allocated in such a manner that is socially acceptable to them. Studies in this area are often missing in the research of ICESs. The objective of this study is to fill in this gap to ensure the costs are allocated to local community members in ICESs in a socially acceptable manner.

The major contributions of this paper are the following:

- Social acceptance is conceptualized in the context of cost allocation in ICESs. It is conceptualized from the perspective of procedural and distributive justice. Both the process and the results of cost allocation are ensured to be fair and socially acceptable to local community members.

- The MCDM method is adopted in this paper as the tool to select a cost allocation method that is socially acceptable to local community members. It is able to provide decision-making on a cost allocation method with various degrees of preference from multi-criteria, multi-alternative, and multi-group decision-making perspectives by using the TOPSIS approach.

- This approach (TOPSIS for social acceptance analysis) can be applied directly to any local energy system without regulation, which is expected to allocate costs among local community members in a socially acceptable manner. Furthermore, this approach is achieved via a quantitative manner, considering the situation that it is not easy to obtain the preferences and opinions from local community members, as there are few pilot projects of ICESs currently.

- The selection of the cost allocation method considers stakeholders involved in cost allocation in ICESs, which addresses the multi-group decision-making environment in the real world. It is useful for local energy system designers, local community members, and investors that participate in the ICES. Furthermore, the approach is generic, indicating that other than the example considered in this paper, the MCDM approach for the selection of cost allocation method is able to apply in different communities considering their preferences with minor adjustments on a case-bycase basis.

\subsection{Structure of the Paper}

The remainder of this paper is organized as: Section 2 conceptualizes social acceptance from the perspective of procedural and distributive justice. Cost allocation methods and their performance are presented in Section 3. Section 4 formulates the multi-group and multi-criteria decision-making problem and the results as well as discussions and policy implications are analyzed in Section 5. Finally, Section 6 concludes the work and outlines future work recommendations. 


\section{Conceptualization of Social Acceptance}

\subsection{Theoretical Background}

Social acceptance covers many aspects and can be expressed in various forms, and it is not an easy task to conceptualize it. One related research is tariff design in large power systems. It is the interconnection between power systems and the end-users by allocating costs to them [34,60]. Regulators make regulatory principles to regulate these activities in order to arrive at a proper tariff design $[33,61]$. These principles are classified into three categories: system sustainability principles, economic efficiency principles, and consumer protection principles $[62,63]$. Detailed information about these regulatory principles can be referred to in the following studies: $[33,34,62,64,65]$. Even though cost allocation in ICESs is not the same as tariff design in large power systems, the concepts of these principles can be translated as the criteria to evaluate how well the costs are allocated. In the context of this research, the main research question is how to design cost allocation in ICESs in a socially acceptable manner. The study in this area is often missing in the literature, especially considering the effects of the procedure and the outcome of cost allocation. Therefore, in this study, social acceptance is conceptualized from the perspective of procedural and distributive justice by ensuring a fair procedure and a fair outcome. The two aspects contribute to the social acceptance of cost allocation. The factors that influence procedural and distributive justice are defined in detail by taking the principles in tariff design in large power systems for reference.

\subsection{Procedural Justice}

Procedural justice is associated with equitable access and participation in the process of decision-making [25,29]. In this section, the factors that may influence the acceptance of cost allocation in ICESs are identified and conceptualized from the following perspectives.

\subsubsection{Transparency}

All the relevant information should be transparent to local stakeholders and protect their privacy at the same time. Firstly, the objectives, procedures, principles, and the approach for allocating costs should be clear to all the stakeholders to ensure that they understand and accept these mechanisms well. Secondly, costs and benefits, energy generation, energy exchange data, and other relevant data associated with the process of cost allocation should be transparent to stakeholders. Thirdly, the resulting consequences of cost allocation should be clear to them to make sure they accept the effects of the cost allocation results. Fourthly, they should be clear about how they are charged for their energy usage.

\subsubsection{Participation}

All the stakeholders are given the right to be able to fully participate in the process and the decision-making of cost allocation. The decision-making issues involved in cost allocation in ICESs include setting goals, making principles, and selecting approaches for allocating costs and other related activities. Full participation in the process of allocating costs helps stakeholders understand how the costs are allocated, and thus increases the acceptance of the cost allocation results and their consequences.

\subsubsection{Accessibility}

All the stakeholders have access to all the relevant information. The information should not be partially accessible to some stakeholders, while not accessible to others. Accessibility is used to ensure that all stakeholders are treated equally.

\subsubsection{Non-Discrimination}

All the stakeholders should be treated equally without discrimination. Firstly, they are engaged in a non-discriminatory way and have equitable access, participation, and strategymaking in the process of cost allocation. Secondly, they should be given equal opportunity 
to express their preferences and opinions. Thirdly, their opinions and suggestions should be taken into consideration equally and treated with respect.

\subsubsection{Consultation}

Considering the different educational backgrounds and understanding levels of local stakeholders, consultation should be provided in the process to ensure they understand the problem. For instance, some local residents may not understand the cost allocation approach well enough that they may not dare to express their opinions or provide constructive suggestions. In this case, they can consultant any problem they have and should get professional answers. Furthermore, the consultation also contributes to active participation in the decision-making process, such as selecting an appropriate cost allocation approach.

\subsection{Distributive Justice}

Distributive justice concerns with a fair distribution of the costs and benefits in ICESs. People may have different measuring standards for fairness, so it is not easy to define fairness directly. In this section, the essential factors influencing distributive justice are defined with an extensive illustration.

\subsubsection{Vertical and Horizontal Equity}

According to the study in [66], the concept of equity is mainly broken down into two aspects: vertical and horizontal equity to evaluate the equitable outcomes in tax policy. Vertical equity means that people who earn more should pay more tax, and horizontal equity means people who earn the same should pay the same tax. While coming back to the case of cost allocation, the energy bills of customers are affected by their consumption behavior. Therefore, we conceptualize vertical and horizontal equity from the perspective of energy consumption. Vertical equity is defined as customers who consume more energy at the same time should pay more, regardless of how the energy is utilized. Horizontal equity is defined as customers who consume the same amount of energy at the same time should pay the same. The underlying principle of the concept is that the method meets the requirement of distributive justice if the cost is allocated based on the energy price of $€ / \mathrm{kWh}$, and this price is the same for each consumer at that moment. It provides a way to evaluated distributive justice intuitively.

\subsubsection{Cost Causality}

The basic concept of cost causality is that the costs should be allocated to those who made it. A cost causality method should reflect the underlying energy bill structure of the energy system. In this paper, the drivers that cause costs are used to define cost causality considering the characteristics of the load profile. The load profile is the basic element in the energy system, and it is the most influencing factor that affects costs. Energy $(\mathrm{kWh})$ and peak demand $(\mathrm{kW})$ are the key elements of the load profile. They are also considered as cost drivers because they reflect the relationship between costs and their causes $[60,62,67]$. Customer service costs are also part of the energy bill representing fixed costs in the cost structure. In this paper, we use energy reflectivity, capacity reflectivity, and customer service reflectivity to represent the three cost drivers. They are the three elements in the assessment of cost causality structure, and they are independent of each other. The assessment approach helps to evaluate to what extent the method reflects cost causality by considering if the billing structure consists of these components.

\subsubsection{Time or Consumption Level Reflectiveness}

Energy consumption has the characteristic of time-varying and repetitiveness over time for households. Peak demand is the main factor that makes the energy system costs very high. Therefore, customers who consume more energy in peak hours should pay more. This could be achieved by providing dynamic charging information in the form of time difference or consumption level difference. 
Time reflectiveness means that the energy price indicates time differences since the load profile is time-dependent. Consumption level reflectiveness has a similar function as time reflectiveness, however, its underlying principle is to provide incentives to users to pay attention to their energy consumption at all the time instead of peak and off-peak hours. They are the economic signals sent to customers to help them adjust their consumption behavior, for example, shifting peak demand to off-peak hours or peak generation hours, limiting electricity consumption within a threshold at any time. This factor contributes to the efficient usage of the energy system.

\subsubsection{Cost Reflectiveness}

Fairness is an essential issue in energy systems, which is the same in the context of cost allocation in ICESs. The costs allocated to local community members should be fair enough to reflect the costs they cause for their energy consumption. Cost reflectiveness is conceptualized as to which extent it reflects the costs local community members should pay [68]. In this study, the costs of investing in DERs by themselves are defined as the cost they should pay since the energy consumption in ICESs is mainly from DERs. This cost is used to compare with the energy bill a customer pays in the ICES to evaluate whether or not the method is cost-reflective.

\subsubsection{Cost Predictability}

The results of cost allocation should remain more or less the same in the short-term (for instance, in two consecutive years) and gradually change in the long-term (for instance, in the lifetime of the energy system) without significant changes in energy generation and consumption. Therefore, the results of cost allocation should be predictable, it is one of the main factors that contributes to the long-term commitment of local community members to stay in ICESs and sustainable and stable development of ICESs. In this study, cost predictability is used to indicate the changes in energy bills in the two consecutive years[68]. Local community members can evaluate if the selected method is cost predictable by comparing the energy costs in the two consecutive years. If the change is small or near zero, it indicates that the method can provide stable cost allocation results without sudden changes in energy bills in the following years.

\subsection{Summary}

The framework of social acceptance is summarized in Figure 2. The framework provides a comprehensive overview of the factors that affect the social acceptance of the involved stakeholders. Procedural justice should be well-followed to ensure the process of allocating costs are acceptable by the local community members and their benefits and rights are well-protected. This should be well-executed by the manager of the community energy system. The criteria affecting distributive justice are possible to be quantified. They have the characteristics of objectivity, which are influenced by the performance of cost allocation methods.

Procedural justice ensures a fair process of allocating costs and increases the acceptance of cost allocation results. A fair procedure is more likely to lead to a fair cost allocation result, and consequently, local community members will show more commitment towards the cost allocation mechanism in ICESs and their long-term relationship with the community. Distributive justice focuses on the outcome of cost allocation, it ensures a fair allocation of costs. A fair outcome is important for cost allocation in ICESs because it maintains the community's well-being. The results are determined by the selected cost allocation method. ICESs are an energy system without regulators that the cost allocation activity is not regulated or guided by the local institution. Therefore, the criteria affecting procedural and distributive justice should be considered the principles to ensure the costs are allocated in a socially acceptable manner. Furthermore, it is essential to take the preferences of local stakeholders into account on these factors when selecting the cost allocation method. The criteria defined above can be used to assess the performance of cost allocation methods 
and select the one that satisfies the preference of local community members, which will be introduced in the following sections. Overall, procedural and distributive justice are indispensable to ensure a socially acceptable cost allocation in ICESs. They are the essential elements to help determine a good cost allocation outcome for the whole community.

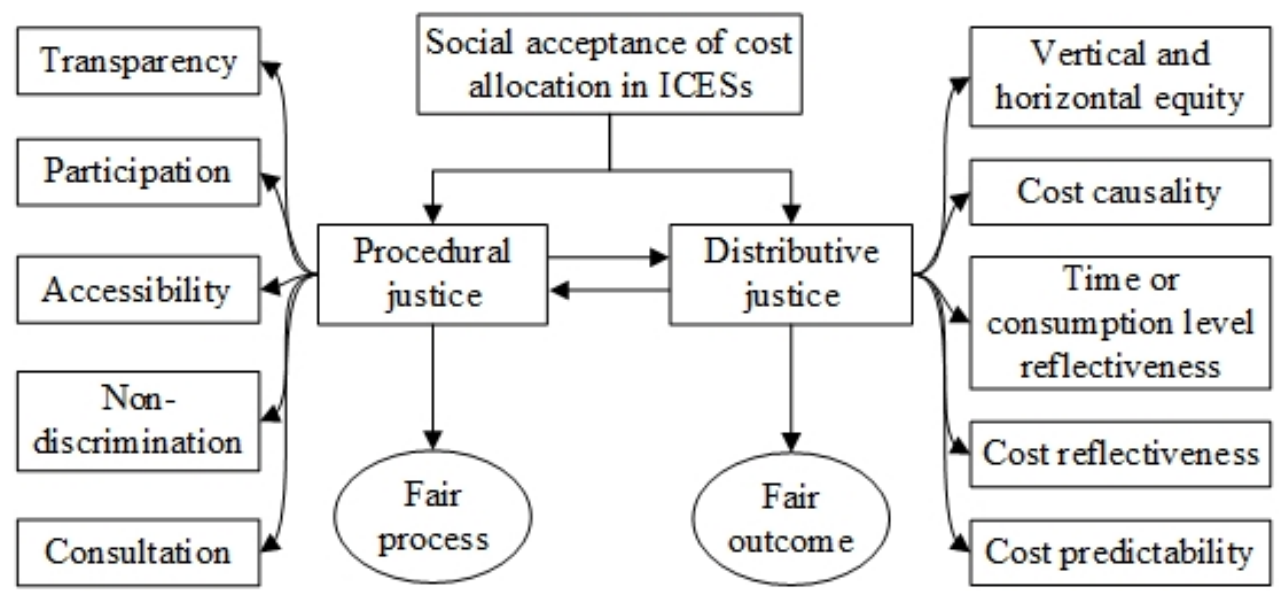

Figure 2. Framework of social acceptance.

\section{Cost Allocation Methods and Performance}

In this section, firstly, the cost allocation methods adopted in this paper are briefly introduced. Then, the performance of cost allocation methods in terms of the criteria defined in Section 2 is analyzed. Ten cost allocation methods are adopted based on the research in [32], and they are summarized in Table 1 by illustrating their main concepts as well as energy bill components.

According to the criteria defined in Section 2 affecting the social acceptance of the results of cost allocation in ICESs, the performance of each method is evaluated in terms of distributive justice. The first three criteria (equity, cost causality, and time or consumption level reflectiveness) are evaluated by the energy bill structure of the cost allocation method. If the energy bill structure includes the criteria as a pricing component, the method satisfies that criterion, otherwise, it does not. For the last two criteria (cost reflectiveness and cost predictability), their values are calculated in the research [32] for each individual customer according to their definition. However, in order to estimate the overall performance of each method, the variance of a set of cost reflectiveness and predictability from individual customers is used. According to their definitions, a value close to zero shows the best performance. Therefore, the value of zero is taken to be the average value in the calculation of variance to see how much the results deviate from the best performance. The variance of cost reflectiveness (or predictability) is calculated by the following equation:

$$
\text { var }_{\text {ref } / \text { pre }_{j}}=\sqrt{\frac{\sum_{i=1}^{N} r e f / \text { pre }_{i, j}{ }^{2}}{N-1}}
$$

where $v a r_{r e f / p r e}$ is the variance of cost reflectiveness (or predictability) of method $j$, ref/ pre $_{i, j}$ is the index for cost reflectiveness (or predictability) of method $j$ for user $i$, $N$ is the number of users. The performance of each cost allocation method in terms of the five criteria analyzed above is summarized in Table 2. 
Table 1. Summary of cost allocation methods.

\begin{tabular}{|c|c|c|}
\hline Cost Allocation Method & Concept & Energy Bill Component \\
\hline $\begin{array}{l}\text { M1: Cost allocation based on the } \\
\text { number of users }\end{array}$ & $\begin{array}{l}\text { Costs are allocated evenly based on the } \\
\text { number of users }\end{array}$ & Fixed cost: Fixed cost: $€ /$ user \\
\hline M2: Flat energy pricing & $\begin{array}{l}\text { Costs are allocated based on the volume of } \\
\text { energy consumption }\end{array}$ & Energy: $€ / \mathrm{kWh}$ \\
\hline M3: Time of use energy pricing & $\begin{array}{l}\text { - Costs are allocated based on the volume } \\
\text { of energy consumption in peak and } \\
\text { off-peak hours } \\
\text { - Price is high during peak hours } \\
\text { - Price is low during off-peak hours }\end{array}$ & $\begin{array}{l}\text { Energy: } € / \text { kWh in peak hours } \\
€ / \text { kWh in off-peak hours }\end{array}$ \\
\hline M4: Capacity subscription & $\begin{array}{l}\text { Costs are allocated based of the capacity of } \\
\text { DERs subscribed by each user }\end{array}$ & Capacity: $€ / \mathrm{kW}$ \\
\hline M5:Coincident peak pricing & $\begin{array}{l}\text { Costs are allocated based on the individual } \\
\text { peak demand happened at the system peak } \\
\text { demand hours }\end{array}$ & Capacity: $€ / \mathrm{kW}$ \\
\hline M6: Non-coincident peak pricing & $\begin{array}{l}\text { Costs are allocated based on the individual } \\
\text { peak demand }\end{array}$ & Capacity: $€ / \mathrm{kW}$ \\
\hline M7: Segmented energy pricing & $\begin{array}{l}\text { - Costs are allocated based on the volume of } \\
\text { energy consumption determined by a threshold } \\
\text { - Price is high for energy consumption over } \\
\text { the threshold } \\
\text { - Price is low for energy consumption within } \\
\text { the threshold } \\
\text { - The threshold is determined by the load factor }\end{array}$ & $\begin{array}{l}\text { Energy: } € / \mathrm{kWh} \text { within in threshold } \\
€ / \mathrm{kWh} \text { over the threshold }\end{array}$ \\
\hline
\end{tabular}

- Costs are allocated based on two factors

- The first factor is the load factor multiplied by

M8: Average and excess method the ratio of average demand of a user and the

Fixed: $€ /$ user sum of the average demand of all users

- The second factor is the complement of the load factor multiplied by the ratio of excess demand of one user and the sum of the excess demand of all users - The excess demand is the difference between the peak demand and the average demand

- Costs are classified between energy- and capacity-

M9: Two-part pricing related based on a coefficient of load factor

- Energy-related costs are allocated based on the coincident peak pricing

- Costs are classified among energy- and capacityand customer service-related costs

M10: Multi-part pricing

- Energy-related costs are allocated based on the volume of energy consumption

- Capacity related costs are allocated based on 
Table 2. Performance assessment of cost allocation methods.

\begin{tabular}{|c|c|c|c|c|c|c|c|}
\hline \multirow{2}{*}{ Cost Allocation Methods } & \multirow{2}{*}{$\begin{array}{l}\text { Vertical and } \\
\text { Horizontal } \\
\text { Equity }\end{array}$} & \multicolumn{3}{|c|}{ Cost Causality } & \multirow{2}{*}{$\begin{array}{l}\text { Time or Consumption } \\
\text { Level Reflectiveness }\end{array}$} & \multirow{2}{*}{$\begin{array}{l}\text { Cost } \\
\text { Reflectiveness }\end{array}$} & \multirow{2}{*}{$\begin{array}{l}\text { Cost } \\
\text { Predictability }\end{array}$} \\
\hline & & $\begin{array}{l}\text { Energy } \\
\text { Reflectivity }\end{array}$ & $\begin{array}{l}\text { Capacity } \\
\text { Reflectivity }\end{array}$ & $\begin{array}{l}\text { Customer Service } \\
\text { Reflectivity }\end{array}$ & & & \\
\hline $\begin{array}{l}\text { M1: Cost allocation based on the } \\
\text { number of users }\end{array}$ & 0 & 0 & 0 & 0 & 0 & 0.30 & 0.00 \\
\hline M2: Flat energy pricing & 1 & 1 & 0 & 0 & 0 & 0.29 & 0.18 \\
\hline M3: Time of use energy pricing & 1 & 1 & 0 & 0 & 1 & 0.20 & 0.18 \\
\hline M4: Capacity subscription & 0 & 0 & 1 & 0 & 0 & 0.20 & 0.18 \\
\hline M6: Non-coincident peak pricing & 0 & 0 & 1 & 0 & 0 & 0.73 & 0.47 \\
\hline M7: Segmented energy pricing & 1 & 1 & 0 & 0 & 1 & 0.37 & 0.24 \\
\hline M8: Average and excess method & 0 & 0 & 1 & 0 & 0 & 0.28 & 0.28 \\
\hline M9: Two-part pricing & 1 & 1 & 1 & 0 & 0 & 0.27 & 0.25 \\
\hline M10: Multi-part pricing & 1 & 1 & 1 & 1 & 0 & 0.26 & 0.19 \\
\hline
\end{tabular}




\section{Multi-Group and Multi-Criteria Decision-Making (TOPSIS)}

In this section, the MCDM method is applied to support the selection of the cost allocation method due to the participation of many local community members with various preferences and many alternatives in the decision-making process.

\subsection{Multiple Decision-Making Groups}

The objective of using MCDM is to help local community members select a socially acceptable cost allocation method. Therefore, it is essential to take local opinions and preferences into account. Local community members vary from each other in education background, financial conditions, employment situations, social concerns, and energy demand level $[11,69]$. They may hold different points of view towards cost allocation based on their situation. Local community members are categorized into several decision-making groups according to their preferences. Members with the same or similar preferences are attributed to the same group. For some decision-making groups, some criteria are more important than others, and they may focus on one or more aspects of the criteria. Therefore, major preferences are considered for each decision-making group in order to simplify the classification.

According to the five criteria defined in Section 2, the first three criteria (equity, cost causality, and time or consumption level reflectiveness) determine if the costs are allocated in a fair manner irrespective of the results. Together, they are considered the major preferences for local community members who are concerned about fair manners. Cost reflectiveness indicates how well the costs are allocated, which is focusing on a fair result. Cost predictability indicates how stable the cost allocation result is in the long-term, which is focusing on stability. Cost reflectiveness and predictability present cost-related issues, but from different dimensions. Local community members may care about one or any combination of these issues; therefore, there exist many decision-making groups. Based on this, the local community members are categorized into seven groups according to their major preferences. The major preferences of the seven decision-making groups are summarized in Table 3. It should be noted that if more criteria and decision-making groups are added, the formulation of the objectives will need to be changed correspondingly, but our proposed methodology is still valid. The seven decision-making groups and their major preferences are now discussed further.

The fairness-focus (Group 1) decision-making group presents the members who are aligned in their preferences that they care if the costs are allocated in a fair manner irrespective of the actual costs assigned to them. The cost reflectiveness-focus group (Group 2) consists of the members who care about the results of cost allocation instead of the allocation process, as long as the final costs reflect the real costs they made for the energy consumption. The cost stability group (Group 3) presents the members who care about the changes in costs in the following years. They do not expect a sudden change in their energy bills provided that their energy demand does not change a lot in the following years. For the following decision-making groups (Groups 4, 5, 6, and 7), it is the combination of the single concerns. The classification of the decision-making groups makes it simple for local community members to express their opinions in practice.

\subsection{TOPSIS for Multi-Group Decision-Making}

The ten cost allocation methods will be assessed based on the major preferences of local community members by using the TOPSIS method. Many steps are involved in the MCDM problem. In this section, the process for multi-group and multi-criteria decisionmaking in the context of cost allocation in ICESs is elaborated step by step to further facilitate the selection of a socially acceptable method. 
Table 3. The major preferences of the seven decision-making groups.

\begin{tabular}{|c|c|c|c|c|c|c|}
\hline \multirow[b]{2}{*}{ Group Number } & \multirow[b]{2}{*}{ Group Name } & \multicolumn{5}{|l|}{ Criteria } \\
\hline & & Equity & Cost Causality & $\begin{array}{l}\text { Time/ } \\
\text { Consumption } \\
\text { Reflectiveness }\end{array}$ & $\begin{array}{l}\text { Cost } \\
\text { Reflectiveness }\end{array}$ & $\begin{array}{l}\text { Cost } \\
\text { Predictability }\end{array}$ \\
\hline 1 & Fairness-focus & $\sqrt{ }$ & $\sqrt{ }$ & $\sqrt{ }$ & & \\
\hline 2 & Cost reflectiveness-focus & & & & $\sqrt{ }$ & \\
\hline 3 & Cost stability-focus & & & & & $\sqrt{ }$ \\
\hline 4 & $\begin{array}{l}\text { Fairness \& cost } \\
\text { reflectiveness-focus }\end{array}$ & $\sqrt{ }$ & $\sqrt{ }$ & $\sqrt{ }$ & $\sqrt{ }$ & \\
\hline 5 & $\begin{array}{l}\text { Fairness \& cost } \\
\text { stability-focus }\end{array}$ & $\sqrt{ }$ & $\sqrt{ }$ & $\sqrt{ }$ & & $\sqrt{ }$ \\
\hline 6 & $\begin{array}{l}\text { Cost reflectiveness \& } \\
\text { stability-focus }\end{array}$ & & & & $\sqrt{ }$ & $\sqrt{ }$ \\
\hline 7 & Perfect-focus & $\sqrt{ }$ & $\sqrt{ }$ & $\sqrt{ }$ & $\sqrt{ }$ & $\sqrt{ }$ \\
\hline
\end{tabular}

Step 1 is to construct the decision-making matrix considering the values $\left(v_{m, n}\right)$ of each criteria $m, \forall m \in M$ for each alternative $n, \forall n \in N$.

Step 2 is to normalize the values of the criteria. Criteria are selected from different aspects and measured on different scales for cost allocation in ICESs. It is necessary to transform them to a common scale to ensure comparability and ranking of alternatives in the decision-making $[70,71]$. Normalization is the process of mapping the values of all criteria, which are measured on different scales, to a common scale and comparable units in the interval [0,1] [72]. It enables the comparison of all criteria measured with different units, and thus to evaluate the performance of each alternative. For the criterion of vertical and horizontal equity and time or consumption level reflectiveness, the values are 0 and 1 , and they are already normalized. Three aspects are included in the criterion of cost causality. The sum of the values of the three aspects is the total value of cost causality. A linear max-min normalization method is used to map these values to the interval $[0,1][73]$ :

$$
N V_{c a u, n}=\frac{v_{c a u, n}-v_{c a u, n, \min }}{v_{c a u, n, \max }-v_{c a u, n, \min }}
$$

where $N V_{c a u, n}$ is the normalization value of cost causality for method $n . v_{c a u, n}$ is the value of cost causality for method $n . v_{c a u, n, \min }$ and $v_{c a u, n, \max }$ are the minimal and maximal values of cost causality for method $n$.

For the criteria of cost reflectiveness and predictability, a variance value is used; therefore, the smaller the value is, the better the performance of the criteria. A linear minmax normalization method is also used to map these values into the interval $[0,1][73]$ :

$$
N V_{\text {ref } / \text { pre }, n}=\frac{v_{\text {ref } / \text { pre }, n, \text { max }}-v_{\text {ref } / \text { pre }, n}}{v_{\text {ref } / \text { pre }, n, \text { max }}-v_{\text {ref } / \text { pre,n,min }}}
$$

where $N V_{\text {ref } / p r e, n}$ is the normalization value of cost reflectiveness (or predictability) for method $n . v_{r e f / p r e, n}$ is the variance value of cost reflectiveness (or predictability) for method n. $v_{\text {ref } / p r e, n, \max }$ and $v_{\text {ref } / \text { pre,n,min }}$ are the maximal and minimal value of cost reflectiveness (or predictability) for method $n$. Thus, a normalization matrix $\left(N V_{m, n}\right)$ contains the normalized value of each criteria for each cost allocation method is obtained.

Step 3 is to define the weighted normalized decision matrix $\left(R_{m, n}^{a}\right)$ for each decisionmaking group $a, \forall a \in A$, where $\mathrm{A}$ is the set of the seven decision-making groups. If the criterion is the major preference for the decision-making group, the weight is assigned to be 1 , otherwise 0 . It is assumed that the weights of all the decision-making groups are 
the same (as the value of 1 ), because the focus of this work is only to show the proposed framework to select a socially acceptable cost allocation by using the TOPSIS method.

$$
R_{m, n}^{a}=w_{m}^{a} N V_{m, n} \quad \forall a \in A, \forall m \in M, \forall n \in N
$$

where $w_{m}^{a}$ is the weight for criteria $m$ for decision-making group $a$.

Step 4 is to find the best point $\left(P_{m}^{a+}\right)$ and the worst point $\left(P_{m}^{a-}\right)$ regarding each criterion $m$ for each decision-making group $a$.

$$
\begin{array}{ll}
P_{m}^{a+}=\max _{\forall n \in N} R_{m, n}^{a} \quad \forall m \in M, \forall a \in A \\
P_{m}^{a-}=\min _{\forall n \in N} R_{m, n}^{a} \quad \forall m \in M, \forall a \in A
\end{array}
$$

Step 5 is to derive the positive distance $S_{n}^{a+}$ and the negative distance $S_{n}^{a-}$ for each alternative $n$ for each decision-making group $a$. The distances are computed by using the Euclidean distance between each alternative and the best or the worst point. A small positive distance and a large negative distance indicate a good solution.

$$
\begin{aligned}
& S_{n}^{a+}=\left(\sum_{\forall m \in M} P_{m}^{a+}-R_{m, n}^{a}\right)^{\frac{1}{2}} \\
& S_{n}^{a-}=\left(\sum_{\forall m \in M} P_{m}^{a-}-R_{m, n}^{a}\right)^{\frac{1}{2}}
\end{aligned}
$$

Step 6 is to calculate the normalized coefficient of closeness (CC) $\left(C C_{n}^{a}\right)$ for each alternative $n$ for each decision-making group $a$. Firstly, the absolute value of CC for each solution $n$ for each decision-making group $a$ is calculated:

$$
\operatorname{ACC}_{n}^{a}=\frac{S_{n}^{a-}}{S_{n}^{a+}+S_{n}^{a-}}
$$

Then, $A C C_{n}^{a}$ is normalized to $C C_{n}^{a}$, which represents the degree of optimality of alternative $n$ for decision-making group $a$. A CC score of 1 means that the solution is the closest to the best alternative, and the furthest to the worst alternative for decision-making group $a$.

$$
C C_{n}^{a}=\frac{A C C_{n}^{a}-A C C_{\min }^{a}}{A C C_{\max }^{a}-A C C_{\min }^{a}} \quad \forall n \in N, \forall a \in A
$$

Step 7 is the final step to combine the preferences of all the decision-making groups, in order to further reach a consistent solution. A geometric mean of the CC scores for all the decision-making groups is calculated to define an average value of $\mathrm{CC}$ score $\left(C C_{n}^{\text {geo-ave }}\right)$ [53]. In the following equation, $A$ is the size of the decision-making groups. The larger the average value is, the better the performance of the alternative.

$$
C C_{n}^{\text {geo-ave }}=\left(\prod_{\forall a \in A} C C_{n}^{a}\right)^{\frac{1}{A}} \quad \forall n \in N
$$

In order to further analyze the results, two more values: maximin and minimax, which are defined by [59], are used. The maximin value indicates that the alternative achieves the highest least satisfaction for the decision-making groups, and the minimax value indicates a risk-neutral solution for the decision-making groups. They are calculated by the following equations:

$$
\begin{aligned}
& \operatorname{maximin}=\max _{\forall n \in N}\left(\min _{\forall a \in A} C C_{n}^{a}\right) \\
& \text { minimax }=\min _{\forall n \in N}\left(\max _{\forall a \in A} C C_{n}^{a}\right)
\end{aligned}
$$




\section{Results and Discussion}

The value of each cost allocation method towards each criterion is obtained based on their performance assessment, and they have then been processed with the MCDM technique (TOPSIS). In this section, the results will be presented.

\subsection{Results}

Firstly, the value of each criterion after normalization is calculated based on the equations in Step 2 and is summarized in Table 4. The CC scores for each decision-making group in terms of the ten alternatives are obtained, as shown in Figure 3. A score of 1 indicates that the alternative is the most desirable and a value of 0 zero indicates the most undesirable for the specific decision-making group based on the overall evaluation of these major preferences among all the alternatives. The main observation is that groups 1, 4, 5, 6 and 7 are well aligned with the best alternative (M3), while the other two groups often have diverging preferences with them. The best alternatives for group 2 are methods 2 and 4 . Furthermore, the best alternative for group 3 is method 1. It is noted that for groups 1, 2, 5 and 6, they have multiple alternatives with the same and the highest CC scores. It indicates that all these alternatives show a better performance in terms of their major preferences. In addition, the best alternatives for groups 2 and 3 are not a good alternative for the other decision-making groups. This is because their major preference is focusing on cost issues instead of fairness issues. The best solution for group 3 (M1) turns out to be a bad solution for other groups. This is because the major preference for the stable-focus group is the stable change in energy bills regardless of costs and fairness issues. Furthermore, method 3 seems to be the most acceptable solution for all decision-making groups, since the least satisfied group still has a score of 0.96 .

Table 4. The value of each criterion after normalization.

\begin{tabular}{|c|c|c|c|c|c|}
\hline $\begin{array}{l}\text { Cost Allocation } \\
\text { Methods }\end{array}$ & nd Horizontal & Cost Causality & $\begin{array}{l}\text { Time or Consumption } \\
\text { Level Reflectiveness }\end{array}$ & Cost Reflectiveness & Cost Predictability \\
\hline $\begin{array}{l}\text { M1: Cost allocation based on the } \\
\text { number of users }\end{array}$ & 0.00 & 0.00 & 0.00 & 0.83 & 1.00 \\
\hline $\begin{array}{l}\text { M2: Flat energy } \\
\text { pricing }\end{array}$ & 1.00 & 0.33 & 0.00 & 1.00 & 0.96 \\
\hline $\begin{array}{l}\text { M3: Time of use } \\
\text { energy pricing }\end{array}$ & 1.00 & 0.33 & 1.00 & 1.00 & 0.96 \\
\hline $\begin{array}{l}\text { M4: Capacity } \\
\text { subscription }\end{array}$ & 0.00 & 0.33 & 0.00 & 1.00 & 0.96 \\
\hline $\begin{array}{l}\text { M5: Coincident peak } \\
\text { pricing }\end{array}$ & 0.00 & 0.33 & 0.00 & 0.00 & 0.00 \\
\hline $\begin{array}{l}\text { M6: Non-coincident } \\
\text { peak pricing }\end{array}$ & 0.00 & 0.33 & 0.00 & 0.68 & 0.88 \\
\hline $\begin{array}{l}\text { M7: Segmented } \\
\text { energy pricing }\end{array}$ & 1.00 & 0.33 & 1.00 & 0.85 & 0.94 \\
\hline $\begin{array}{l}\text { M8: Average and } \\
\text { excess method }\end{array}$ & 0.00 & 0.33 & 0.00 & 0.86 & 0.93 \\
\hline M9: Two-part pricing & 1.00 & 0.67 & 0.00 & 0.89 & 0.94 \\
\hline $\begin{array}{l}\text { M10: Multi-part } \\
\text { pricing }\end{array}$ & 1.00 & 1.00 & 0.00 & 0.94 & 0.95 \\
\hline
\end{tabular}




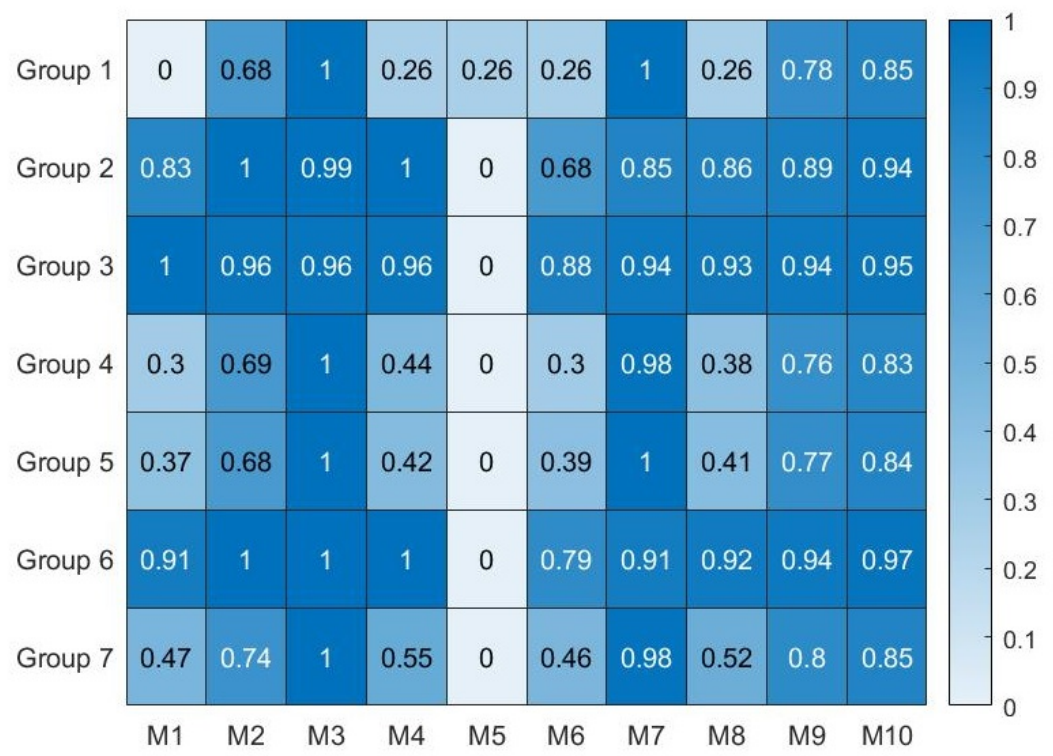

Figure 3. The CC score of each decision-making group in terms of the ten alternatives.

In practice, only one cost allocation method is required to allocate costs in ICESs; therefore, besides the best solutions for each decision-making group, it is essential to arrive at an alternative that considers all the groups involved in the local community. In this study, the single solution is quantified using the geometric average solution, maximin solution, and minimax solution. It shows the solution combining all the major preferences of the decisionmaking groups. The average $\mathrm{CC}$ score for each alternative considering all the decision-making groups in terms of the three solutions is shown in Figure 4. It is noted that for the first two solutions, the highest average CC score is the best alternative and the lowest score is the best alternative for the last solution (minimax solution), as shown in the red circle.
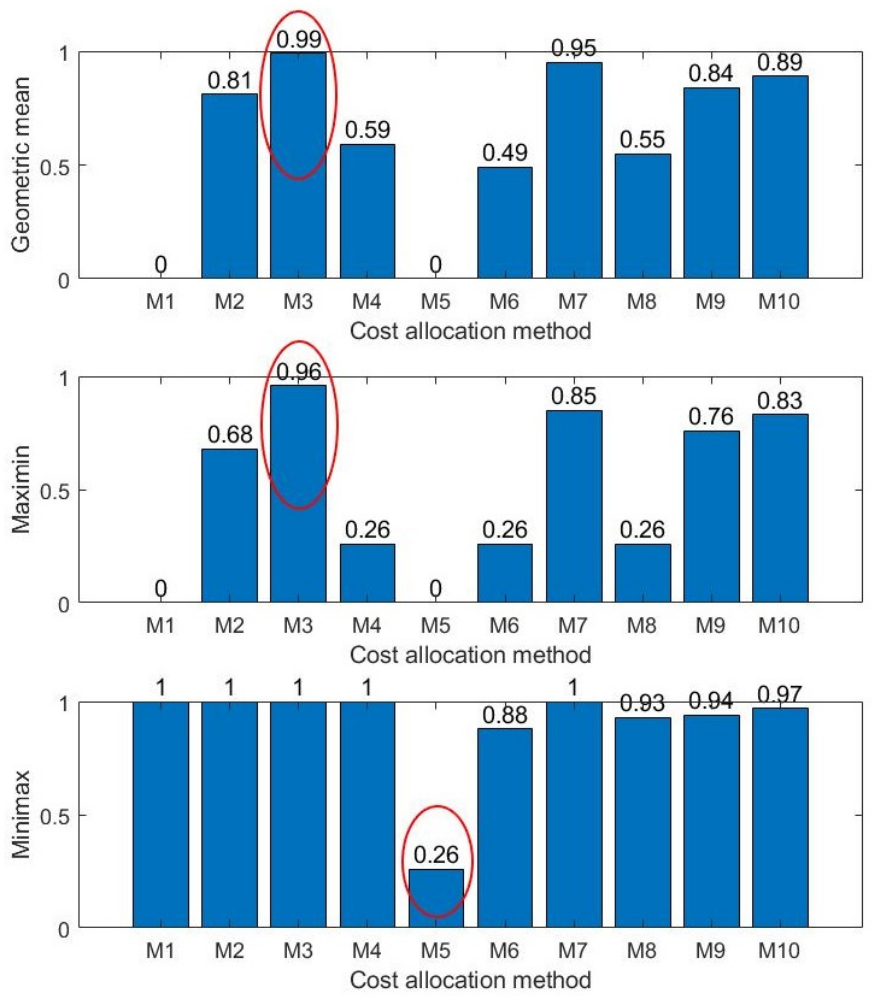

Figure 4. The average CC scores for each alternative considering all the decision-making groups for the three solutions. 
The geometric average solution is calculated based on Equation (11). Method 3 has the highest average CC score among the ten alternatives. It is the most desirable cost allocation method combining all the major preferences of the seven decision-making groups. Furthermore, method 7 is comparable with this solution.

The maximin solution is calculated based on Equation (12). It may not be the best, but it is acceptable for every local community member in ICESs. The maximin solution is calculated by taking the minimal CC score of the seven decision-making groups first, and then taking the highest minimal CC score. Therefore, it has the highest least satisfaction for the decision-making group. Compared to the average solution, method 3 has the highest maximin score. It corresponds to the results presented in Figure 3 that method 3 is the most desirable solution for the seven decision-making groups.

The minimax solution is calculated based on Equation (13). It also considers the least regret solution that all the decision-making groups will have the least regret after decision-making. Method 5 turns out to be the least regretful solution. This solution only shows the features that follow the criterion of cost causality in terms of capacity reflectivity. Considering the CC score of each decision-making group shown in Figure 3, it is the last best solution for the other decision-making groups except group 1. Even though it is the least regretful solution, it may not a good solution for all the decision-making groups.

In practice, the composition of the community may be different, and there may be more or fewer decision-making groups in the community. In this case study, we take groups 1 and 6 as the two decision-making groups in the community. Group 1 cares about if the costs are allocated in a fair manner, and group 6 cares about the results of cost allocation, as long as the results reflect the cost they should pay in actuality and the energy bills are stable in the long-term. The average solution for the two decision-making groups is shown in Figure 5. The results show that method 3 is the best solution combining the major preferences for the two decision-making groups. Our approach works with different decision-making groups. Once the decision-making groups are determined, it is easy to apply the approach proposed in this paper to support the local community members in selecting a cost allocation method satisfying their requirements.

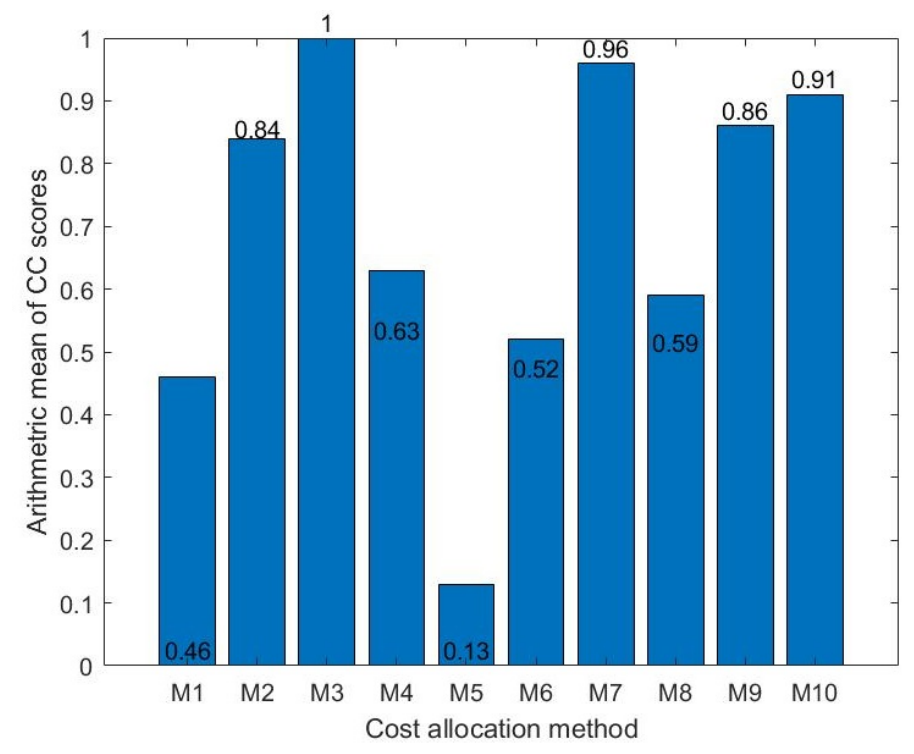

Figure 5. The average solution for the decision-making groups 1 and 6 .

In this study, it is assumed that the number of local community members (weight of each decision-making group) in each group is equal. This assumption is made because the main objective of this work is to show the adoption of the MCDM tool to solve the decisionmaking problem. However, the changes in the weights of the decision-making groups may have effects on the final results. In order to see how this would influence the results, an analysis with different percentages of local community members in decision-making 
groups 1 and 6 is introduced, as shown in Table 5. The percentages are translated to the weights of the two decision-making groups. The geometric mean cannot be used because it multiplies all the values together. Instead, the arithmetic mean is used to calculate the average score for all the two decision-making groups. The average solution for the five scenarios is shown in Figure 6. The results show that the best solution for the whole community is influenced by the percentage of local community members in the decisionmaking group. The best solution is method 3 for the five scenarios considered in the research. However, it should be noted that the average score of methods 5 and 7 increases with the increase in the percentage of group 1, and method 7 tends to be the best solution when group 1 takes the majority (90\% in this case). Furthermore, when group 6 takes the majority (which is also 90\%), method 2 tends to be the second-best alternative. The analysis done here indicates that MCDM is an effective tool to help local community members select a method that is socially acceptable to them.

Table 5. Scenarios with different percentages of local community members in each group.

\begin{tabular}{lccccc}
\hline Scenarios & S1 (\%) & S2 (\%) & S3 (\%) & S4 (\%) & S5(\%) \\
\hline Group 1 & 10 & 30 & 50 & 70 & 90 \\
\hline Group 6 & 90 & 70 & 50 & 30 & 10 \\
\hline
\end{tabular}

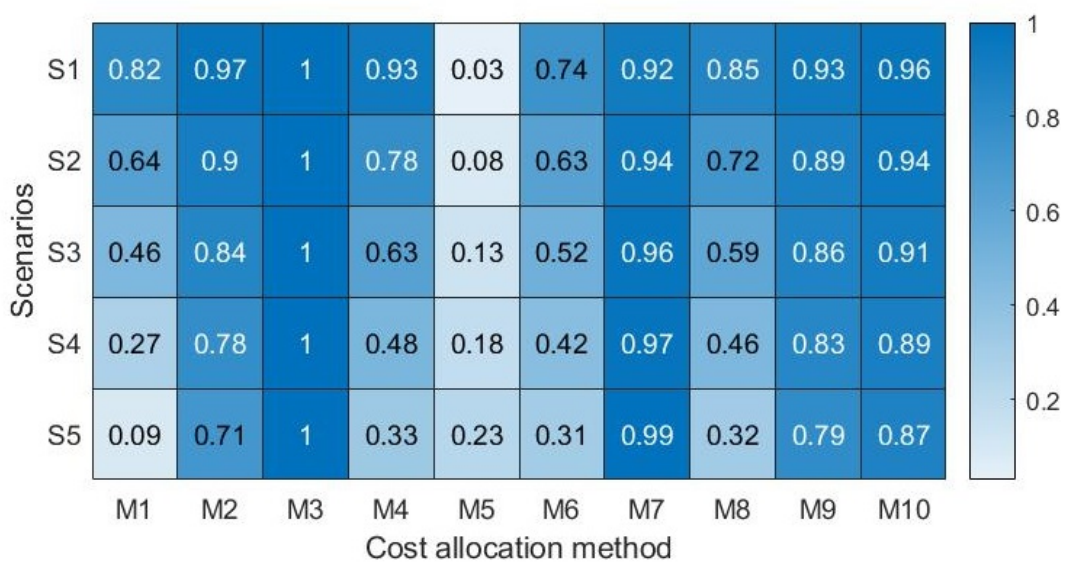

Figure 6. The analysis for different weights assigned to the decision-making groups.

This section shows the results of the MCDM problem of selecting a socially acceptable cost allocation method by using the TOPSIS method. The performance of cost allocation methods is assessed based on their characteristics. The local community is categorized into different decision-making groups considering the differences in their major preferences. Seven decision-making groups are considered in this study, and their major preferences vary from fairness, cost reflectiveness to stability and any combination of them. The numerical results show that method 3 is the best solution for the seven decision-making groups considered in this research. Furthermore, method 7 is the second-best alternative yet acceptable for local community members. They cover relatively more comprehensive aspects of the five criteria compared to the other methods. In addition, the analysis of the weight of different decision-making groups indicates that the number of local community members in different decision-making groups influences the selection of best solutions. The approach proposed in this paper can effectively deal with the changes in the number and the weights of decision-making groups, thus, provides a reliable solution to the local community.

\subsection{Discussion}

In the field of cost allocation in local community energy systems, the research on cost allocation is often missing. In addition, the engagement of local community members is 
an essential element in local community energy systems. Their involvement is the key factor that affects the success of the implementation of local community energy systems. The costs should be allocated in a socially acceptable manner in any local community energy system without regulation. However, the research on social acceptance is often addressed in the area of renewable energy technologies. In this study, a social acceptance framework is designed from the perspective of procedural and distributive justice to ensure a relatively fair process and result. A fair process increases the acceptance of the results of cost allocation, and a fair result increases the acceptance of the cost allocation procedure. Procedural justice and distributive justice interact with each other, they are the essential criteria that are required to follow to ensure that the costs are allocated in a socially acceptable manner. In this paper, ten methods are adopted as the alternatives to allocate costs in ICESs, they are assessed in terms of the five criteria: equity, cost causality, time or consumption level reflectiveness, cost reflectiveness, and cost predictability.

Allocating costs in ICESs in a socially acceptable manner is a complex and difficult issue, where local community members need to reach an agreement on a cost allocation method. They have different preferences and interests that sometimes conflict with each other, which are the major reasons that affect the success of cost allocation. It is also difficult to specify the preferences of each local community member, therefore, it is essential to classify them into several decision-making groups to simplify the process of collecting opinions from local community members. Therefore, it stands for a multi-group, multicriteria, and multi-alternative decision-making problem. Seven decision-making groups are classified in this study according to the major preferences of local community members. The problem is solved by adopting the MCDM (TOPSIS) method to help the local community members to select a socially acceptable cost allocation method. Three solutions (geometric mean, maximin, and minimax) are obtained, combining all the major preferences of the seven decision-making groups. The results show that TOPSIS is an effective tool to solve the social acceptance problem in cost allocation in ICESs from the multi-group perspective. The advantages of applying the MCDM method lie in that: (1) it simplifies the process of collecting opinions from local community members by considering decision-making groups, the only thing the local community members should do is to select the decisionmaking group, (2) it is able to consider the preferences of all the decision-making groups in the selection of cost allocation method simultaneously, (3) social acceptance is achieved by a quantitative measurable manner, and (4) the approach is still valid when more decisionmaking groups are added. It makes it easy for local community members to select a socially acceptable cost allocation method by using the proposed approach, which is also convenient for local managers to arrange these issues when allocating costs in ICESs. The obtained results can be used by any local stakeholder in local community energy systems in the decision-making process to select a method, which can lead to a relatively fair cost allocation result, and thus socially acceptable to them. The MCDM analysis selects a cost allocation method that follows the criteria that affect distributive justice, which further affects the social acceptance of the results of cost allocation. However, procedural justice is also an essential factor that cannot be neglected in practice to ensure a fair process.

\subsection{Policy Implications}

ICESs are social-technical systems with physical and social network relationships. These systems are complex in the sense that they require decision-making from multiinstitutional levels. A successful cost allocation in ICESs requires support from local authorities, local government, policymakers, regulators, system operators, and other related parties. Besides, a local community energy market committee should be established, which may consist of several experts in the energy market to regulate the cost allocation activities.

For local authorities or government, the approach proposed in this paper provides them with promising policy-relevant results, which can be considered the instruments to manage the local community energy market to ensure both the process and the results of cost allocation are socially acceptable to local community members. Policymakers and local 
regulators should make appropriate policies and regulations to regulate cost allocation activities in local community energy systems. Besides, they should send proper incentives and design supportive schemes to support local community energy markets. They should acknowledge the value the local community members can bring to the energy systems and the environment. Overall, tailored regulations should be made specifically for the context of local community energy markets, to provide them with sufficient autonomy to take full control of their energy systems. The support from local authorities can better contribute to the participation of local community members in the energy transition.

Considering the current situation, it is not realistic to have a 100\% renewable energy system to achieve self-sufficiency, the local community energy systems still require support from system operators. They are required to distribute energy and maintain local energy systems with a safe, reliable, and affordable grid. Besides, ICESs should be given certain policy support to have access to fair energy trading with the grid, such as reasonable feed-in tariff and export tariff to ensure their benefits.

For local community members, the approach provides them with the opportunity to fully participate in the process of cost allocation. Furthermore, this also provides them with a sense of community belonging. The involvement of local community members, on one hand, increases the complexity of the cost allocation process, because a lot of local opinions and preferences are required to be taken into account. The cost allocation mechanisms, methods, and affecting factors should be well-explained to local community members by following procedural justice. The designed framework of social acceptance in this study can support this well. At the same time. It also requires the local community managers to map these preferences properly and carefully into the problem. However, on the other hand, once these issues are settled, they are more willing to accept the results, because the costs are already allocated in a socially acceptable manner to satisfy their overall preferences and requirements. Considering this point, it is beneficial for local managers or coordinators to manage the local community energy markets. Besides, a proper institution design should be promised since a collective decision has to be made to meet the individual requirements.

Regarding the cost allocation methods, ten possible alternatives are adopted in this research, and in the future, with the maturation of the local community energy market, regulators should develop more methods and provide more options for local community members to choose from. Besides, the social acceptance framework proposed in this study provides the local community energy market with strong regulation guidance to regulate the activity of cost allocation. To some extent, they can be considered the principles to follow when allocating costs in local energy systems. The MCDM method adopted in this research can be added to the policy package as one option to achieve socially acceptable cost allocation in the local community energy market.

\section{Conclusions and Future Work}

\subsection{Conclusions}

The costs should be allocated in a socially acceptable manner in any local community energy system without regulation. The study in this paper presents a systematic framework for the analysis of social acceptance of cost allocation in ICESs. Social acceptance is mainly affected by two aspects: procedural justice and distributive justice. Procedural justice ensures a fair process, while distributive justice ensures a fair result. Both aspects interact with each other and are indispensable in order to achieve the goal of allocating costs in a socially acceptable manner. The MCDM technique (TOPSIS) adopted in this paper is a good representative tool to help local community members to select a socially acceptable cost allocation method. The framework can be used by local stakeholders in local community energy systems in the decision-making process to select a socially acceptable method. The social acceptance analysis done in this study contributes to the development of local community energy systems from a socio-economic perspective. 


\subsection{Future Work}

In this study, we considered ten cost allocation methods and analyzed their performance according to the criteria defined in this paper. In future work, firstly, it is interesting to involve more cost allocation methods, which can further provide more options for local stakeholders to select. Secondly, it is also worth investigating other criteria that would affect the fairness of cost allocation results. Thirdly, the MCDM method considered in this study is the TOPSIS method because the objective is to present a basic framework for analyzing the social acceptance of cost allocation in ICESs. The major preferences are explicit, which might be ambiguous in reality; therefore, the fuzzy TOPSIS method can be applied in future work to take ambiguity into account. Besides, seven decision-making groups are classified in this research based on the criteria defined in the dimension of distributive justice, it is possible to add more decision-making groups to make it more accurate to represent the preferences of local community members.

Author Contributions: N.L.: conceptualization, methodology, investigation, writing-original draft, writing-review and editing, visualization. R.H.: conceptualization, supervision, writing-review and editing. Z.L.: supervision, writing-review and editing. All authors have read and agreed to the published version of the manuscript.

Funding: This research received no external funding.

Institutional Review Board Statement: Not applicable.

Informed Consent Statement: Not applicable.

Data Availability Statement: Not applicable.

Acknowledgments: The authors wish to acknowledge the China Scholarship Council (CSC) and the Energy and Industry group in the Department of Engineering Systems and Services at Delft University of Technology for financial support of the first author.

Conflicts of Interest: The authors declare no conflict of interest.

\section{References}

1. Basak, P.; Chowdhury, S.; Nee Dey, S.H.; Chowdhury, S. A literature review on integration of distributed energy resources in the perspective of control, protection and stability of microgrid. Renew. Sustain. Energy Rev. 2012, 16, 5545-5556. [CrossRef]

2. Eid, C.; Bollinger, L.A.; Koirala, B.; Scholten, D.; Facchinetti, E.; Lilliestam, J.; Hakvoort, R. Market integration of local energy systems: Is local energy management compatible with European regulation for retail competition? Energy 2016, 114, 913-922. [CrossRef]

3. Koirala, B.P.; Chaves Ávila, J.P.; Gómez, T.; Hakvoort, R.A.; Herder, P.M. Local alternative for energy supply: Performance assessment of integrated community energy systems. Energies 2016, 9, 981. [CrossRef]

4. Mendes, G.; Ioakimidis, C.; Ferrão, P. On the planning and analysis of Integrated Community Energy Systems: A review and survey of available tools. Renew. Sustain. Energy Rev. 2011, 15, 4836-4854. [CrossRef]

5. Koirala, B.P. Integrated Community Energy Systems. Ph.D. Thesis, Delft University of Technology, Delft, The Netherlands, 2017.

6. Koirala, B.P.; Koliou, E.; Friege, J.; Hakvoort, R.A.; Herder, P.M. Energetic communities for community energy: A review of key issues and trends shaping integrated community energy systems. Renew. Sustain. Energy Rev. 2016, 56, 722-744. [CrossRef]

7. Koirala, B.P.; Hakvoort, R.A.; Âvila, J.P.C.; Gómez, T. Assessment of Integrated Community Energy Systems. In Proceedings of the 2016 13th International Conference on the European Energy Market (EEM), Porto, Portugal, 6-9 June, 2016; pp. 1-6.

8. Li, N.; Hakvoort, R.A.; Lukszo, Z. Cost allocation in integrated community energy systems-A review. Renew. Sustain. Energy Rev. 2021, 144, 111001. [CrossRef]

9. Koirala, B.; Hakvoort, R. Integrated Community-Based Energy Systems: Aligning Technology, Incentives, and Regulations. In Innovation and Disruption At the Grid's Edge; Elsevier: Amsterdam, The Netherlands, 2017; pp. 363-387.

10. Shamsuzzoha, A.; Grant, A.; Clarke, J. Implementation of renewable energy in Scottish rural area: A social study. Renew. Sustain. Energy Rev. 2012, 16, 185-191. [CrossRef]

11. Tsoutsos, T.; Drandaki, M.; Frantzeskaki, N.; Iosifidis, E.; Kiosses, I. Sustainable energy planning by using multi-criteria analysis application in the island of Crete. Energy Policy 2009, 37, 1587-1600. [CrossRef]

12. Guan, J.; Zepp, H. Factors Affecting the Community Acceptance of Onshore Wind Farms: A Case Study of the Zhongying Wind Farm in Eastern China. Sustainability 2020, 12, 6894. [CrossRef]

13. Vuichard, P.; Stauch, A.; Dällenbach, N. Individual or collective? Community investment, local taxes, and the social acceptance of wind energy in Switzerland. Energy Res. Soc. Sci. 2019, 58, 101275. [CrossRef] 
14. Maleki-Dizaji, P.; Del Bufalo, N.; Di Nucci, M.R.; Krug, M. Overcoming barriers to the community acceptance of wind energy: Lessons learnt from a comparative analysis of best practice cases across Europe. Sustainability 2020, 12, 3562. [CrossRef]

15. Walter, G. Determining the local acceptance of wind energy projects in Switzerland: The importance of general attitudes and project characteristics. Energy Res. Soc. Sci. 2014, 4, 78-88. [CrossRef]

16. Dimitropoulos, A.; Kontoleon, A. Assessing the determinants of local acceptability of wind-farm investment: A choice experiment in the Greek Aegean Islands. Energy Policy 2009, 37, 1842-1854. [CrossRef]

17. Musall, F.D.; Kuik, O. Local acceptance of renewable energy-A case study from southeast Germany. Energy Policy 2011, 39, 3252-3260. [CrossRef]

18. Wüstenhagen, R.; Wolsink, M.; Bürer, M.J. Social acceptance of renewable energy innovation: An introduction to the concept. Energy Policy 2007, 35, 2683-2691. [CrossRef]

19. Wolsink, M. Distributed energy systems as common goods: Socio-political acceptance of renewables in intelligent microgrids. Renew. Sustain. Energy Rev. 2020, 127, 109841. [CrossRef]

20. Roddis, P.; Carver, S.; Dallimer, M.; Norman, P.; Ziv, G. The role of community acceptance in planning outcomes for onshore wind and solar farms: An energy justice analysis. Appl. Energy 2018, 226, 353-364. [CrossRef]

21. Devine-Wright, P.; Wiersma, B. Understanding community acceptance of a potential offshore wind energy project in different locations: An island-based analysis of 'place-technology fit'. Energy Policy 2020, 137, 111086. [CrossRef]

22. Roddis, P.; Roelich, K.; Tran, K.; Carver, S.; Dallimer, M.; Ziv, G. What shapes community acceptance of large-scale solar farms? A case study of the UK's first 'nationally significant'solar farm. Sol. Energy 2020, 209, 235-244. [CrossRef]

23. De Luca, E.; Nardi, C.; Giuffrida, L.G.; Krug, M.; Di Nucci, M.R. Explaining Factors Leading to Community Acceptance of Wind Energy. Results of an Expert Assessment. Energies 2020, 13, 2119. [CrossRef]

24. Forman, A. Energy justice at the end of the wire: Enacting community energy and equity in Wales. Energy Policy 2017, 107, 649-657. [CrossRef]

25. Mundaca, L.; Busch, H.; Schwer, S. 'Successful'low-carbon energy transitions at the community level? An energy justice perspective. Appl. Energy 2018, 218, 292-303. [CrossRef]

26. Pesch, U.; Correljé, A.; Cuppen, E.; Taebi, B. Energy justice and controversies: Formal and informal assessment in energy projects. Energy Policy 2017, 109, 825-834. [CrossRef]

27. Gross, C. Community perspectives of wind energy in Australia: The application of a justice and community fairness framework to increase social acceptance. Energy Policy 2007, 35, 2727-2736. [CrossRef]

28. Sovacool, B.K.; Dworkin, M.H. Energy justice: Conceptual insights and practical applications. Appl. Energy 2015, 142, 435-444. [CrossRef]

29. Williams, S.; Doyon, A. Justice in energy transitions. Environ. Innov. Soc. Trans. 2019, 31, 144-153. [CrossRef]

30. Jørgensen, M.L.; Anker, H.T.; Lassen, J. Distributive fairness and local acceptance of wind turbines: The role of compensation schemes. Energy Policy 2020, 138, 111294. [CrossRef]

31. Walker, G. Beyond distribution and proximity: Exploring the multiple spatialities of environmental justice. Antipode 2009, 41, 614-636. [CrossRef]

32. Li, N.; Hakvoort, R.A.; Lukszo, Z. Cost allocation in integrated community energy systems: Performance assessment. unpublished.

33. Ortega, M.P.R.; Pérez-Arriaga, J.I.; Abbad, J.R.; González, J.P. Distribution network tariffs: A closed question? Energy Policy 2008, 36, 1712-1725. [CrossRef]

34. Abdelmotteleb, I.; Gómez, T.; Ávila, J.P.C.; Reneses, J. Designing efficient distribution network charges in the context of active customers. Appl. Energy 2018, 210, 815-826. [CrossRef]

35. Demirtas, O. Evaluating the best renewable energy technology for sustainable energy planning. Int. J. Energy Econ. Policy 2013, $3,23$.

36. Troldborg, M.; Heslop, S.; Hough, R.L. Assessing the sustainability of renewable energy technologies using multi-criteria analysis: Suitability of approach for national-scale assessments and associated uncertainties. Renew. Sustain. Energy Rev. 2014, 39, 1173-1184. [CrossRef]

37. Pohekar, S.D.; Ramachandran, M. Application of multi-criteria decision making to sustainable energy planning-A review. Renew. Sustain. Energy Rev. 2004, 8, 365-381. [CrossRef]

38. Cavallaro, F. An Integrated Multi-Criteria System to Assess Sustainable Energy Options: An Application of the PROMETHEE Method. Available at SSRN 666741. 2005. Available online: https://papers.ssrn.com/sol3/papers.cfm?abstract_id=666741 (accessed on 3 September 2021)

39. Ghafghazi, S.; Sowlati, T.; Sokhansanj, S.; Melin, S. A multicriteria approach to evaluate district heating system options. Appl. Energy 2010, 87, 1134-1140. [CrossRef]

40. Baumann, M.; Weil, M.; Peters, J.F.; Chibeles-Martins, N.; Moniz, A.B. A review of multi-criteria decision making approaches for evaluating energy storage systems for grid applications. Renew. Sustain. Energy Rev. 2019, 107, 516-534. [CrossRef]

41. Murrant, D.; Radcliffe, J. Assessing energy storage technology options using a multi-criteria decision analysis-based framework. Appl. Energy 2018, 231, 788-802. [CrossRef]

42. Kumar, A.; Sah, B.; Singh, A.R.; Deng, Y.; He, X.; Kumar, P.; Bansal, R. A review of multi criteria decision making (MCDM) towards sustainable renewable energy development. Renew. Sustain. Energy Rev. 2017, 69, 596-609. [CrossRef] 
43. Runsten, S.; Nerini, F.F.; Tait, L. Energy provision in South African informal urban Settlements-A multi-criteria sustainability analysis. Energy Strategy Rev. 2018, 19, 76-84. [CrossRef]

44. Vasić, G. Application of multi criteria analysis in the design of energy policy: Space and water heating in households-City Novi Sad, Serbia. Energy Policy 2018, 113, 410-419. [CrossRef]

45. Wang, J.J.; Jing, Y.Y.; Zhang, C.F.; Zhao, J.H. Review on multi-criteria decision analysis aid in sustainable energy decision-making. Renew. Sustain. Energy Rev. 2009, 13, 2263-2278. [CrossRef]

46. Arce, M.E.; Saavedra, Á.; Míguez, J.L.; Granada, E. The use of grey-based methods in multi-criteria decision analysis for the evaluation of sustainable energy systems: A review. Renew. Sustain. Energy Rev. 2015, 47, 924-932. [CrossRef]

47. Abu-Taha, R. Multi-criteria applications in renewable energy analysis: A literature review. In Proceedings of the 2011 Proceedings of PICMET'11: Technology Management in the Energy Smart World (PICMET), Portland, OR, USA, 31 July-4 August, 2011; pp. $1-8$.

48. Lemos Bulhões, R.; Souza de Santana, E.; Álisson Bandeira Santos, A. Use of Analytic Hierarchy Process for Wind Farm Installation Region Prioritization-Case Study. Energies 2020, 13, 2284. [CrossRef]

49. Ren, J.; Dong, L. Evaluation of electricity supply sustainability and security: Multi-criteria decision analysis approach. J. Clean. Prod. 2018, 172, 438-453. [CrossRef]

50. Hussain Mirjat, N.; Uqaili, M.A.; Harijan, K.; Mustafa, M.W.; Rahman, M.; Khan, M.; others. Multi-criteria analysis of electricity generation scenarios for sustainable energy planning in Pakistan. Energies 2018, 11, 757. [CrossRef]

51. Cavallaro, F. Multi-criteria decision aid to assess concentrated solar thermal technologies. Renew. Energy 2009, 34, 1678-1685. [CrossRef]

52. Yue, Z. A method for group decision-making based on determining weights of decision makers using TOPSIS. Appl. Math. Model. 2011, 35, 1926-1936. [CrossRef]

53. Shih, H.S.; Shyur, H.J.; Lee, E.S. An extension of TOPSIS for group decision making. Math. Comput. Model. 2007, 45, 801-813. [CrossRef]

54. Pan, X.; Wang, Y. An Enhanced Technique for Order Preference by Similarity to Ideal Solutions and its Application to Renewable Energy Resources Selection Problem. Int. J. Fuzzy Syst. 2020, 23, 1087-1101. [CrossRef]

55. Solangi, Y.A.; Tan, Q.; Mirjat, N.H.; Ali, S. Evaluating the strategies for sustainable energy planning in Pakistan: An integrated SWOT-AHP and Fuzzy-TOPSIS approach. J. Clean. Prod. 2019, 236, 117655. [CrossRef]

56. Boran, F.E.; Genç, S.; Kurt, M.; Akay, D. A multi-criteria intuitionistic fuzzy group decision making for supplier selection with TOPSIS method. Expert Syst. Appl. 2009, 36, 11363-11368. [CrossRef]

57. Memari, A.; Dargi, A.; Jokar, M.R.A.; Ahmad, R.; Rahim, A.R.A. Sustainable supplier selection: A multi-criteria intuitionistic fuzzy TOPSIS method. J. Manuf. Syst. 2019, 50, 9-24. [CrossRef]

58. Yu, C.; Shao, Y.; Wang, K.; Zhang, L. A group decision making sustainable supplier selection approach using extended TOPSIS under interval-valued Pythagorean fuzzy environment. Expert Syst. Appl. 2019, 121,1-17. [CrossRef]

59. Wang, N.; Heijnen, P.W.; Imhof, P.J. A multi-actor perspective on multi-objective regional energy system planning. Energy Policy 2020, 143, 111578. [CrossRef]

60. Reneses, J.; Rodríguez, M.P.; Pérez-Arriaga, J. Electricity tariffs. In Regulation of the Power Sector; Springer: London, UK, 2013; pp. 397-441.

61. Abdelmotteleb, I. Designing Electricity Distribution Network Charges for an Efficient Integration of Distributed Energy Resources and Customer Response. Ph.D. Thesis, KTH Royal Institute of Technology, Stockholm, Sweden, 2018.

62. Reneses, J.; Gómez, T.; Rivier, J.; Angarita, J.L. Electricity tariff design for transition economies: Application to the Libyan power system. Energy Econ. 2011, 33, 33-43. [CrossRef]

63. Picciariello, A.; Reneses, J.; Frias, P.; Söder, L. Distributed generation and distribution pricing: Why do we need new tariff design methodologies? Electr. Power Syst. Res. 2015, 119, 370-376. [CrossRef]

64. Koliou, E.; Bartusch, C.; Picciariello, A.; Eklund, T.; Söder, L.; Hakvoort, R.A. Quantifying distribution-system operators' economic incentives to promote residential demand response. Util. Policy 2015, 35, 28-40. [CrossRef]

65. Reneses, J.; Ortega, M.P.R. Distribution pricing: Theoretical principles and practical approaches. IET Gener. Transm. Distrib. 2014, 8, 1645-1655. [CrossRef]

66. Hodgson, H. Theories of Distributive Justice: Frameworks for Equity. J. Australas. Tax Tchrs. Ass'n 2010, 5, 86.

67. Bharatkumar, A. Distribution Network Use-of-System Charges Under High Penetration of Distributed Energy Resources. Ph.D. Thesis, Massachusetts Institute of Technology, Cambridge, MA, USA, 2015.

68. Nijhuis, M.; Gibescu, M.; Cobben, J. Analysis of reflectivity \& predictability of electricity network tariff structures for household consumers. Energy Policy 2017, 109, 631-641.

69. Safari, M.A.M.; Masseran, N.; Jedi, A.; Mat, S.; Sopian, K.; Bin Abdul Rahim, A.; Zaharim, A. Rural Public Acceptance of Wind and Solar Energy: A Case Study from Mersing, Malaysia. Energies 2020, 13, 3855. [CrossRef]

70. Vafaei, N.; Ribeiro, R.A.; Camarinha-Matos, L.M. Normalization techniques for multi-criteria decision making: Analytical hierarchy process case study. In Doctoral Conference on Computing, Electrical and Industrial Systems; Springer: Cham, UK, 2016; pp. 261-269.

71. Vafaei, N.; Ribeiro, R.A.; Camarinha-Matos, L.M. Data normalisation techniques in decision making: Case study with TOPSIS method. Int. J. Inf. Decis. Sci. 2018, 10, 19-38. [CrossRef] 
72. Pavličić, D. Normalization affects the results of MADM methods. Yugosl. J. Oper. Res. 2001, 11, 251-265.

73. Chakraborty, S.; Yeh, C.H. A simulation based comparative study of normalization procedures in multiattribute decision making. In Proceedings of the 6th Conference on 6th WSEAS International Conference on Artificial Intelligence, Knowledge Engineering and Data Bases, Corfu Island, Greece, 16-19 February 2007; Volume 6, pp. 102-109. 